\title{
Uma Análise Crítica sobre os Antecedentes da Interseccionalidade
}

\author{
Gabriela M. Kyrillos' \\ 0000-0001-7237-4210 \\ 'Universidade Federal do Rio Grande, Faculdade de Direito, Santa Vitória do Palmar, \\ RS, Brasil.96230-000 - direito@furg.br
}

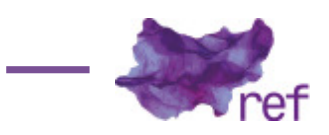

Resumo: A maior utilização da interseccionalidade no campo dos estudos de gênero tem se revelado de grande importância para a melhor compreensão das relações múltiplas e simultâneas de desigualdade. Paralelamente a isso, em particular no Brasil, é possível identificar uma tendência ao apagamento da história e dos debates teóricos que existiam antes da interseccionalidade ser nomeada por Kimberlé Crenshaw, em 1989. Consciente dessa lacuna, nesta pesquisa, de caráter bibliográfico, tem-se por objetivo realizar um apanhado geral do contexto anterior ao surgimento do termo interseccionalidade, esperando, com isso, contribuir para a manutenção do caráter crítico e transformador do conceito, além de evidenciar as lutas e produções teóricas de mulheres negras, tão frequentemente minimizadas e apagadas dentro da teoria feminista.

Palavras-chove: Interseccionalidade; teoria feminista; feminismo negro; gênero; raça.

A Critical Analysis of the Background of Intersectionality

Abstract: The greater use of the intersectionality in the field of gender studies has proved to be of great importance for a better understanding of the multiple and simultaneous relations of inequality. On the other hand, particularly in Brazil, there is a notable erasure of the history and the theoretical debates that existed before intersectionality was named by Kimberlé Crenshaw in 1989. Aware of this gap, this bibliographic research aims at a general overview of the context that existed prior to the emergence of intersectionality, therefore hoping to contribute to the maintenance of the critical and transformative character of the term, as well as to highlight the struggles and theoretical productions of black women, so often minimized and erased within feminist theory.

Key-words: Intersectionality; Feminist Theory; Black Feminism; Gender; Race.

\section{Introdução}

A interseccionalidade é um conceito que tem ganhado cada vez mais espaço nos debates e nas pesquisas acadêmicas, inclusive no Brasil. Foi Kimberlé Crenshaw, jurista estadunidense, quem a nomeou em 1989 e quem, posteriormente, desenvolveu algumas das mais importantes elaborações teóricas sobre esse conceito. São recorrentes, portanto, as pesquisas que partem da(s) obra(s) de Crenshaw e utilizam a interseccionalidade como um conceito analítico, na medida em que este serve de forma bastante eficaz quando se trata de analisar contextos e teorias a partir de uma perspectiva que abarque outras categorias além do gênero. A ruptura com uma visão monolítica de análise e sua popularização é, sem dúvida, uma das grandes contribuições dos estudos que utilizam a teoria da interseccionalidade.

A interseccionalidade pode ser entendida como uma ferramenta de análise que consegue dar conta de mais de uma forma de opressão simultânea. Com essa lente, os processos discriminatórios não são compreendidos isoladamente, nem se propõem uma mera adição de discriminações, mas sim, abraça-se a complexidade dos cruzamentos dos processos discriminatórios e a partir daí se busca compreender as condições específicas que deles decorrem. 
Apesar dessa ampliação na utilização do conceito, o que se verifica recorrentemente, em particular no Brasil, é o apagamento da história e dos debates teóricos que existiam antes da interseccionalidade ser nomeada por Crenshaw. Esse apagamento se torna especialmente grave quando se observa que a origem da interseccionalidade está relacionada com as lutas sociais e as elaborações teóricas de mulheres negras. Por essa razão, é preciso que se reconheça a importância de uma análise crítica sobre a origem da interseccionalidade. Para isso, é fundamental partir do entendimento de que a ideia basilar que a interseccionalidade transmite é uma preocupação que existia dentro dos movimentos sociais e de textos teóricos desde muito antes do surgimento do conceito da interseccionalidade e de sua apropriação pelo mundo acadêmico.

Assim sendo, nesta pesquisa, de caráter bibliográfico, tem-se por objetivo realizar um apanhado geral do contexto anterior ao surgimento da interseccionalidade. Sem nenhuma pretensão de esgotar uma temática tão ampla nestas poucas páginas, busca-se apenas trazer algumas das muitas formas possíveis de compreensão do cenário no qual surgiu o conceito da interseccionalidade. Para isso, na pesquisa serão perpassados elementos históricos e teóricos do Brasil e dos Estados Unidos, apresentando-se subdividida em dois momentos: em primeiro lugar, serão abordados brevemente os feminismos negros; e, em segundo, os debates anteriores a 1989 acerca das ideias fundamentais da interseccionalidade. Desse modo, espera-se que o caráter crítico da interseccionalidade possa ser preservado e fortalecido.

\section{As questões raciais e os feminismos negros}

Existem distintas formas de abordar um tema tão complexo como os feminismos negros. Opta-se, aqui, por iniciar reconhecendo que falar de movimentos de pessoas negras impõe uma reflexão sobre a história do povo afrodescendente. De acordo com Patricia Hill Collins (2012), é importante destacar que se trata de refletir sobre a história de pessoas que sofreram o processo diaspórico, ou seja, vivenciaram experiências que perpassam a escravidão, o colonialismo, o imperialismo e a migração forçada. Quando se trata de refletir sobre os feminismos negros a partir do Brasil, impõe-se, também, a necessidade de se conhecer a história do povo negro no país. No livro Lugar de Negro, de Lélia Gonzalez e Carlos Hasenbalg (1982), encontra-se uma importante análise da história do país. A partir dessa obra, é possível compreender a transição da população negra de um regime de brutal escravidão, durante o período colonial, para um local na sociedade capitalista que surgia e que, apesar de romper com a escravidão institucionalizada e legalizada, ainda era permeado por inúmeras desigualdades estruturais.

Assim, Gonzalez e Hasenbalg (1982, p. 15) destacam como os porões, as favelas, os cortiços e as invasões são marcas de uma história pautada pela divisão racial do espaço. Denunciando a naturalização das desigualdades sociais, ainda destacam outros dois locais tidos como naturais às pessoas negras: a cadeia e o hospício (GONZALEZ; HASENBALG, 1982, p. 15-16). Além disso, vale mencionar a importância que tem um aparato policial baseado em ideias racistas e classistas na imposição do medo. "A longo prazo, o que se pretende é o impedimento de qualquer forma de unidade e organização do grupo dominado, mediante a utilização de todos os meios que perpetuem sua divisão interna" (GONZALEZ; HASENBALG, 1982, p. 16). Esse trecho do livro é dedicado a pensar a sociedade brasileira durante o período ditatorial militar de 1964 a 1985, mas pode ser ainda perfeitamente aplicável para a forma como a polícia reproduz uma violência institucional de modo significantemente maior na população negra. ${ }^{1}$

Durante a ditadura militar no Brasil, ocorreu o que a antropóloga brasileira Lélia Gonzalez (1982, p. 30) denominou como a desarticulação das elites intelectuais negras. Um exemplo disso foi o autoexílio a que se impôs Abdias do Nascimento, uma das pessoas mais importantes na articulação da luta e do movimento negro no país, sendo um dos fundadores do Teatro Experimental do Negro, do Museu da Arte Negra e do Instituto de Pesquisas e Estudos Afro-Brasileiros, tendo também contribuído para o surgimento do Memorial Zumbi e do Movimento Negro Unificado.

Apesar de o país estar vivendo uma ditadura militar, em 1976 foi ministrado o primeiro curso de cultura negra no Brasil pela própria Gonzalez (1982, p. 40). Isso demonstra o quão recentemente o tema da racialidade se tornou uma pauta dentro do campo acadêmico e científico no país, enquanto em outros locais, como nos Estados Unidos, a raça já se fazia presente como uma importante categoria analítica nas pesquisas em ciências humanas e sociais.

\footnotetext{
' No Brasil, a violência institucional (aquela cometida por agente ou órgão estatal) está bastante atrelada ao racismo institucional, que, juntos, promovem no país o que a Anistia Internacional denominou como criminalização da pobreza, um processo que "[...] tem se manifestado de vários modos: policiamento baseado em 'invasões' de comunidades carentes ou favelas, geralmente utilizando mandados coletivos que discriminam comunidades inteiras com um único golpe; níveis extremos de violações de direitos humanos, inclusive execuções extrajudiciais e tortura; corrupção extensiva praticada por integrantes da polícia; e o fracasso em oferecer as formas mais básicas de proteção, efetivamente abandonando as pessoas socialmente excluídas nas mãos de gangues criminosas e facções do tráfico" (AMNESTY INTERNATIONAL. 'Eles entram atirando': Policiamento de comunidades socialmente excluídas. Brasil, 2005. Disponível em: http://www.ovp-sp.org/relatorio_anistiai_eles_entram_atirando.pdf. Acesso em 02/08/2017).
} 
De acordo com Gonzalez (1982, p. 19), o movimento negro brasileiro não é unificado, não produz suas lutas por meio de consensos absolutos. Essa afirmação é importante pois não se limita ao movimento negro brasileiro, sendo uma característica fundamental dos movimentos sociais e dos feminismos negros de um modo geral. Como elucida a estadunidense Collins (2012, p. 108), é importante que se atente para o fato de que as diferenças existentes entre as mulheres negras acabam por produzir diferentes padrões de conhecimento experiencial que, por sua vez, produzem reações diversas diante de questões como racismo e sexismo. Desse modo, Collins (2012, p. 112) afirma que, ao contrário de consensos, o que existe é um ponto de vista coletivo das mulheres negras que é marcado pelas tensões que surgem quando se busca dar respostas aos desafios que lhes são comuns.

Assim sendo, mesmo quando Gonzalez (1982, p. 49) traça, em sua obra, um histórico do movimento negro no Brasil, ela o faz sempre destacando o caráter plural e nem sempre pacífico das disputas internas que levaram ao surgimento e à atuação de grupos como o Movimento Unificado Contra a Discriminação Racial. Do mesmo modo, a elaboração do arcabouço teórico que hoje é considerado como parte dos feminismos negros envolveu e envolve muitas disputas e a busca por uma construção coletiva capaz de respeitar as diversidades existentes dentro de um grupo tão plural como são as mulheres negras. Essas diferenças históricas e sociais geram diferenças nas atuações desses movimentos, e um exemplo notório dessa diferença é a forma como nos Estados Unidos houve a segregação racial e no Brasil se perpetuou o mito da democracia racial; e como os movimentos negros e as mulheres negras articularam suas lutas dentro de contextos tão diferentes.

Nos Estados Unidos, após o fim da escravidão, o país viveu de 1876 a 1965 um período de segregação racial que impunha espaços reservados exclusivamente para pessoas brancas e pessoas negras, nos mais variados contextos públicos e privados, durante todo o período em que vigorou o que ficou conhecido como Jim Crow laws. Estas legislações estaduais ou federais institucionalizavam a segregação racial. Portanto, quando se narra que no início do século XX as mulheres estavam próximas de conseguir o direito ao voto, as mulheres negras viviam uma experiência totalmente diferente daquela vivida pelas mulheres brancas estadunidenses.

A filósofa estadunidense Angela Davis abordou essa temática em sua obra clássica Mulheres, Raça e Classe, publicada originalmente em 1981 e, no Brasil, pela primeira vez, em 2016. Davis aborda como para as mulheres negras na "crescente ideologia da feminilidade do século XIX, que enfatizava o papel das mulheres como mães protetoras, parceiras e donas de casa amáveis para seus maridos, as mulheres negras eram praticamente anomalias" (Angela DAVIS, 2016, p. 29). Eram em sua maioria mulheres acostumadas com o trabalho árduo que a escravidão impôs e que, mesmo após o seu fim, a sociedade continuava a impor, já que não havia outras oportunidades de sobrevivência para as mulheres negras em uma sociedade profundamente racista e sexista.

Esse local específico no qual se encontravam as mulheres negras, mesmo quando o movimento feminista se expandia nos Estados Unidos e buscava lutar pelos direitos das mulheres, fez com que a participação daquelas no movimento fosse pautada por diversos momentos de silenciamento. A dominância das mulheres brancas e a falta de empatia da maior parte delas fizeram com que muitas vezes fossem incapazes de perceber o quanto as principais bandeiras do feminismo naquele momento ignoravam as vivências das mulheres negras. Em uma corajosa tentativa de demonstrar que existiam muitas formas de ser mulher naquela sociedade, Sojourner Truth fez um dos discursos mais famosos da luta antirracista e antissexista. Truth, que foi escravizada por 40 anos e viveu outros 40 como uma mulher livre, subiu ao palco na primeira Convenção Nacional pelos Direitos das Mulheres nos Estados Unidos, em 1852.

"Não sou eu uma mulher?" Com uma voz que soava como "o eco de um trovão", ela disse:
"Olhe para mim! Olhe para o meu braço", e levantou a manga para revelar a "extraordinária
força muscular" de seu braço. "Arei a terra, plantei, enchi os celeiros, e nenhum homem podia
se igualar a mim! Não sou eu uma mulher? Eu podia trabalhar tanto e comer tanto quanto um
homem - quando eu conseguia comida - e aguentava o chicote da mesma forma! Não sou
eu uma mulher? Dei à luz treze crianças e vi a maioria ser vendida como escrava e, quando
chorei em meu sofrimento de mãe, ninguém, exceto Jesus, me ouviu! Não sou eu uma mulher?"
(DAVIS, 2016, p. 97).

A importância do discurso de Sojourner Truth é enorme para o movimento feminista como um todo e, em especial, para os feminismos negros. De acordo com a antropóloga Mercedes Jabardo Velasco (2012, p. 29), se fosse necessário citar apenas um 'texto' fundacional dos feminismos negros, esse seria o discurso de Sojourner Truth em 1852.

Encontramos nele alguns dos aspectos que permitem entender o caráter contra-hegemônico deste movimento. Em primeiro lugar, a oralidade do relato frente à racionalidade da escrita dos textos fundacionais do feminismo branco. A oralidade, e também a oratória aprendida e praticada nos púlpitos das igrejas. Ambas ferramentas de resistência dos grupos subalternos. Em segundo lugar, as próprias características da oradora: Sojourner Truth foi a primeira de uma importante saga 
de intelectuais negras que, sem o apoio de uma obra escrita, conectaram-se com os interesses e as lutas das mulheres negras. Em terceiro lugar, por ser um texto criado desde a colonialidade. Desde aí, com uma linguagem própria que não se vê refletida no espelho imposto, Sojourner Truth desconstrói a categoria (hegemônica) de mulher - uma categoria desde a qual a nega reivindicando sua própria identidade enquanto mulher. A intersecção da "raça" com o gênero, que desde o sistema hegemônico constrói as mulheres negras como não-mulheres, re-aparece no discurso de Sojourner em termos inclusivos. Por trás de sua "Por acaso não sou uma mulher?", por trás da luta de outras ex-escravas como Harriet Jacobs, aparece um desejo que pulsa por resignificar o termo mulher. Sua aspiração era ser livre, não apenas da opressão racista, mas também da dominação sexista (VELASCO, 2012, p. 30). ${ }^{2}$

Desse modo, entre o final do século XIX e a primeira metade do século XX, o debate sobre o racismo se fez muito presente nos Estados Unidos. Os linchamentos ${ }^{3}$ e a segregação eram formas gritantes e evidentes de um racismo que se exercia cotidianamente e que era inegável, mesmo por pessoas que tentassem ignorar tal racismo estrutural. Tais violações fizeram com que os anos da década de 1890 fossem, de acordo com Angela Davis (2016), "[...] os mais difíceis para a população negra desde a abolição da escravatura, e as mulheres se sentiam naturalmente obrigadas a se juntar à luta de resistência de seu povo" (p. 104). O impacto dessas violações nas vidas das mulheres fez com que estas se unissem para denunciar tais atrocidades. "Foi em reação à desenfreada onda de linchamentos e ao abuso sexual indiscriminado de mulheres negras que as primeiras associações de mulheres negras foram estabelecidas" (DAVIS, 2016, p. 107). Ou seja, como é inegável, o contexto social e histórico que viveram as mulheres negras nos Estados Unidos influenciou o surgimento do feminismo negro naquele país. Do mesmo modo, a história brasileira se relaciona com a trajetória do movimento negro nacional, sendo a ideia de que há no Brasil uma democracia racial - um dos mais perpetuados mitos sobre as relações raciais no país.

A falácia de que existe uma democracia racial no Brasil advém da compreensão de que se trata de um país formado pela 'mistura' de raças diferentes (ameríndios, africanos e europeus), que fazem com que sua população seja, em sua esmagadora maioria, fruto da mestiçagem, o que, portanto, eliminaria os preconceitos raciais. Essa formulação é, em parte, tributária do livro de Gilberto Freyre (2006), Casa-Grande e Senzala, que, ao abordar a história do Brasil e seu período colonial e escravocrata, coaduna com a ideia de que foi majoritariamente positivo o resultado do encontro das diferentes raças e culturas. As contribuições de Gonzalez sobre a análise de Freyre são bastante relevantes na medida em que demonstram como, para o autor, as mulheres negras só eram vistas como boas quando exerciam o papel de amas de leite, por ele denominadas como "mães pretas", fazendo com que Gonzalez (1984) afirme que "nessa hora a gente é vista como figura boa e vira gente" (p. 235). Partindo dessa compreensão, a autora faz uma interessante reflexão sobre as negras enquanto mães dessa cultura que se construiu e que historicamente nega e invisibiliza a importância das mulheres negras.

Outro autor relevante para a construção do mito da democracia racial brasileira é Darcy Ribeiro (1980), que tendo como uma de suas referências Gilberto Freyre, compreende que a conjunção das "[...] matrizes culturais indígena, africana e européia [...]" (p. 140) foi capaz de gerar "[...] algumas células culturais novas com respeito àquelas matrizes originais e, depois, para fundi-las numa proto-etnia com a qual toda a população se vai identificando" (RIBEIRO, 1980, p. 140). Darcy Ribeiro chega mesmo a compreender que passa a existir no Brasil uma "nova etnia nacional" (RIBEIRO, 1980, p. 141).

A mestiçagem foi na história brasileira e de outros países latino-americanos tão importante que gerou a ideia de que é "[...] impossível a determinação exata do status racial da maioria dos atuais latino-americanos" (Kabengele MUNANGA, 2010, p. 444). O antropólogo nascido no Congo e radicado no Brasil, Kabengele Munanga, compreende a mestiçagem como o símbolo da identidade brasileira e analisa algumas de suas implicações. Uma dessas implicações é que, para que se suponha que o encontro das diferentes raças e culturas no país geraria um povo mestiço tipicamente brasileiro há, intrinsecamente, o entendimento de "[...] anulação das

\footnotetext{
${ }^{2}$ No original: "Encontramos en el algunos de los rasgos que permiten entender el carácter contra-hegemónico de este movimiento. En primer lugar, la oralidad del relato frente a la racionalidad de la escritura de los textos fundacionales del feminismo blanco. La oralidad, y también la oratoria aprendida y practicada en los púlpitos de las iglesias. Ambas, herramientas de resistencia de los grupos subalternos. En segundo lugar, el propio carácter de la oradora: Sojourner Truth fue la primera de una importante saga de intelectuales negras que, sin el apoyo de una obra escrita, han conectado con los intereses y las luchas de las mujeres negras. En tercer lugar, por ser un texto creado desde la colonialidad. Desde ahí, con un lenguaje propio que no se ve reûejado en el espejo impuesto, Sojourner Truth deconstruye la categoría (hegemónica) de mujer - una categoría desde la que se la niega - reivindicando su propia identidad en tanto que mujer. La intersección de la "raza" con el género, que desde el sistema hegemónico construye a las mujeres negras como no-mujeres, re-aparece en el discurso de Sojourner en términos inclusivos. Detrás de su "¿Acaso no soy una mujer?", detrás de las luchas de otras ex esclavas como Harriet Jacobs, aparece un anhelo que pugna por re-signiûcar el término mujer. Su aspiración era ser libres, no sólo de la opresión racista, sino también de la dominación sexista" (VELASCO, 2012, p. 30).

${ }^{3}$ Sobre os violentos e arbitrários linchamentos que ocorriam com homens negros nos Estados Unidos, ver: Angela Davis (2016).
} 
identificações étnicas de índios, africanos e europeus [...]" e a "[...] indiferenciação entre as várias formas de mestiçagem" (MUNANGA, 2010, p. 445).

Essa anulação das especificidades das diversas culturas dos povos que se encontraram no Brasil no período colonial ocorreu historicamente de modo sistemático por parte do Estado brasileiro. Um exemplo notório disso foram as políticas voltadas para os povos indígenas no Brasil que, até a Constituição Federal de 1988, reproduziam o paradigma assimilacionista (Gabriela KYRILLOS; Sheila STOLZ, 2013). O assimilacionismo é uma das diversas violências que os povos de culturas não eurocêntricas sofreram no Brasil e a incorporação de algumas de suas características à ideia de uma identidade nacional em regra serviu para promover a ideia falaciosa de que haveria uma pacífica cultura tipicamente brasileira.

Ignorar o propósito político de branqueamento e homogeneização existente por trás do processo de miscigenação no Brasil é um dos aspectos que tornou e ainda torna tão difícil discutir questões raciais no país. Por essa razão, quando Joyce Souza Lopes (2013) escreve algumas pontuações e proposições às pessoas brancas e à luta antirracista, ela afirma que "o principal desafio, sobre a compreensão da identidade branca, está relacionado à louvação da mistura racial, a positivação do Mito de Democracia Racial e sua tentativa de branqueamento via miscigenação" (p. 144). Conforme afirmou Avtar Brah (2006), "a racialização da subjetividade branca não é muitas vezes manifestamente clara para os grupos brancos, porque 'branco' é um significante de dominância, mas isso não torna o processo de racialização menos significativo" (p. 345).

No caso brasileiro, defender o mito da democracia racial é negar um violento processo assimilacionista imposto aos povos africanos e indígenas, ao mesmo tempo que desconsidera as implicações atuais de uma sociedade que se construiu historicamente com base em um ainda presente racismo estrutural. Somente reconhecendo esses elementos é possível tratar o "[...] racismo enquanto um problema relacional, e não como um problema de negros[as]" (LOPES, 2013, p. 142) e reconhecer que os privilégios em razão da raça que todas as pessoas brancas possuem na sociedade atual estão relacionados a essa valorização histórica do branqueamento.

Compreender o processo de branqueamento como uma política adotada pelo Estado brasileiro por diversos meios, inclusive genocídios de uma ou mais culturas inteiras, impõe a necessidade de se pensar o país como tendo um histórico de racismo igualmente violento e abominável, como aquele dos países que implantaram leis de segregação racial. Até porque não se trata de comparar experiências para dizer que algumas foram menos brutais que outras, mas sim de afirmar que "[...] todos os racismos são abomináveis. Mas cada um deles tem uma dinâmica particular que conduz a resultados e a consequências diferentes na luta de suas vítimas" (MUNANGA, 2010, p. 449).

Rompe-se, portanto, com a ideia de uma raça brasileira, ou seja, abandonam-se ideais de uma raça pura, "[...] que biologicamente nunca existiu em nenhum país do mundo, se aplicaria muito menos ainda a um país tão mestiçado como o Brasil" (MUNANGA, 2010, p. 453). O que o reconhecimento da pluralidade étnica e cultural do Brasil pretende demonstrar é que confundir o aspecto biológico da mestiçagem (isto é, a miscigenação) "[...] e o fato transcultural dos povos envolvidos nessa miscigenação com o processo de identificação da identidade, cuja essência é fundamentalmente político-ideológica, é cometer um erro epistemológico notável" (MUNANGA, 2010 , p. 453). Somente ao reconhecer esses elementos é possível produzir discussões sobre raça que percebam o caráter relacional dessas estruturas.

Não se trata, portanto, apenas de superar o mito da democracia racial, mas sim de construir novas formas de reflexão sobre a questão racial no Brasil, de modo que considere como a história do país produziu privilégios para umas (pessoas brancas) e prejuízos para outras (pessoas não brancas). Sendo assim, o conceito de raça, já tantas vezes aqui citado, não deve ser entendido como foi utilizado do século XVI ao XIX. Trata-se de um conceito pautado na lógica apresentada pelos movimentos negros contemporâneos e por algumas e alguns intelectuais das Ciências Sociais, ou seja, parte-se de uma nova interpretação, tal qual apresentada por Nilma Lino Gomes (2005, p. 45), que se baseia na dimensão social e política do conceito de raça. Entende-se, portanto, que o uso do termo raça é uma escolha política adequada para o Brasil, na medida em que a forma como se dá a discriminação racial no país se desenvolve não apenas a partir de elementos da identidade étnica de determinado grupo, mas também em razão dos aspectos físicos possíveis de serem observados na estética corporal dos membros desse grupo. Ou seja, "[...] raça ainda é o termo que consegue dar a dimensão mais próxima da verdadeira discriminação contra os[as] negros[as], ou melhor, do que é o racismo que afeta as pessoas negras da nossa sociedade" (GOMES, 2005, p. 45).

A utilização do termo raça é, portanto, uma escolha política que assume a compreensão de que há racismo no Brasil e que ele se desenvolveu e se perpetua hoje de forma bastante particular. De acordo com Gomes (2005), o racismo brasileiro “[...] se afirma através da sua própria negação" (p. 46), por meio da defesa do mito da democracia racial. Isso fez com que o racismo no país fosse alicerçado em uma constante e profunda contradição. Enquanto a sociedade brasileira 
nega a existência do racismo, "[...] as pesquisas atestam que, no cotidiano, nas relações de gênero, no mercado de trabalho, na educação básica e na universidade os[as] negros[as] ainda são discriminados[as] e vivem uma situação de profunda desigualdade racial" (GOMES, 2005, p. 46).

Nesse cenário histórico, as mulheres negras estiveram sempre em um local específico. Como bem observou Sueli Carneiro (1995), "o estupro colonial da mulher negra pelo homem branco no passado e a miscigenação daí decorrente criaram as bases para a fundação do mito da cordialidade e democracia racial brasileira" (p. 546). A violência sofrida pelas mulheres negras e as denúncias e lutas dela decorrentes fazem com que essas mulheres ocupem um local específico no qual é preciso enfrentar "[...] no interior do próprio movimento feminista, as contradições e as desigualdades que o racismo e a discriminação racial produzem entre as mulheres, particularmente entre negras e brancas no Brasil" (CARNEIRO, 2003, p. 120). De modo semelhante, também tiveram que enfrentar a ausência de "[...] solidariedade de gênero intragrupo racial que conduziu as mulheres negras a exigirem que a dimensão de gênero se instituísse como elemento estruturante das desigualdades raciais na agenda dos Movimentos Negros Brasileiros" (CARNEIRO, 2003, p. 120). Em outras palavras, as mulheres negras brasileiras que atuavam tanto no movimento feminista, quanto no movimento negro, já denunciavam o que posteriormente foi nomeado como discriminação interseccional.

Os impactos nas lutas das mulheres negras ao lidarem simultaneamente com demandas de um país racista e sexista estão, dentre outros, nas denúncias do eurocentrismo do movimento feminista que se consolidou no século XX no Brasil. É possível afirmar que uma das principais contribuições do feminismo negro no país foi justamente questionar a visão eurocêntrica, ocidental e universal das mulheres na qual o feminismo predominante tanto se fundamentava, conforme destacado pela filósofa brasileira Sueli Carneiro (2003). Essas bases são verdadeiras limitações do feminismo mainstream, já que "[...] as vozes silenciadas e os corpos estigmatizados de mulheres vítimas de outras formas de opressão além do sexismo continuaram no silêncio e na invisibilidade" (CARNEIRO, 2003, p. 118). Os feminismos negros, em certa medida, desestabilizam alguns dos pressupostos nos quais se fundamentava o feminismo existente até então.

Os questionamentos não se restringem apenas aos limites do conceito de mulher como algo uno. Eles são múltiplos, já que, como dito anteriormente, são múltiplas as experiências e concepções das mulheres negras que o formam. Vale mencionar o questionamento ao próprio termo gênero, com sua pretensão supostamente universal, já que se trataria de um conceito "[...] particular a políticas de mulheres anglófonas/americanas e brancas, especialmente nos Estados Unidos" (Oyèrónké OYìùMí, 2004, p. 3). Essas críticas a conceitos tão basilares da teoria e da prática feminista vêm de autoras afro-americanas que insistem que não é possível considerar o gênero de modo separado dos conceitos de raça e classe. "Esta posição levou à insistência sobre as diferenças entre as mulheres e a necessidade de teorizar múltiplas formas de opressão, particularmente sobre as quais as desigualdades de raça, gênero e as desigualdades de classe são evidentes" (OYìù̀í, 2004, p. 3). ${ }^{4}$ Daí é possível compreender como os feminismos negros foram os terrenos fundamentais e necessários para o surgimento do conceito de interseccionalidade.

Quando se trata da luta das mulheres negras em outros países, outras categorias surgem como igualmente relevantes para as análises sobre desigualdades de gênero, como afirmou Oyiwùmí (2004): "[...] as discussões centraram-se sobre a necessidade de atentar-se ao imperialismo, à colonização e outras formas locais e globais de estratificação, que emprestam peso à afirmação de que o gênero não pode ser abstraído do contexto social e outros sistemas de hierarquia" (p. 3). Isto decorre do fato de que cada contexto histórico produziu distintas formas estruturais de racismo que implicam limitações ao movimento feminista, visto que

as mulheres brancas que dominam o discurso feminista - as quais, na maior parte, fazem e formulam a teoria feminista - têm pouca ou nenhuma compreensão da supremacia branca como estratégia, do impacto psicológico da classe, de sua condição política dentro de um Estado racista, sexista e capitalista (bell hooks, 2015, p. 196).

A dominância das mulheres brancas no movimento feminista brasileiro é bastante evidenciada no texto de Carneiro (2003), quando a autora observa como alguns dos pontos que foram pautas do movimento feminista e que supostamente diziam respeito a todas as mulheres na verdade eram aspectos específicos da vivência de mulheres brancas. Um exemplo disso é a

\footnotetext{
${ }_{4}^{4}$ Para Oyèrónké Oyìwùmí, a limitação do gênero decorre de uma limitação anterior existente no feminismo branco, que é a centralidade do conceito de família nuclear. "Metodologicamente, a unidade de análise é o lar da família nuclear, o que, teoricamente, então, reduz mulher à esposa. Porque raça e classe não são normalmente variáveis na família, faz sentido que o feminismo branco, que está preso na família, não veja raça ou classe. Assim, a categoria fundamental da diferença, que aparece como um universal a partir dos limites da família nuclear, é o gênero. A mulher no centro da teoria feminista, a esposa, nunca fica fora do domicílio. Como um caracol, ela carrega a casa em torno de si mesma. O problema não é que a conceituação feminista comece com a família, mas que ela nunca transcenda os estreitos limites da família nuclear. Consequentemente, sempre que mulher está presente, torna-se a esfera privada da subordinação das mulheres. Sua própria presença define-a como tal" (OYìùMí, 2004, p. 5).
} 
problematização da concepção cristã segundo a qual a mulher é um subproduto do homem, na medida que teria surgido de sua costela. Esse elemento, tão presente na cultura europeia, é um pressuposto específico da religião cristã, não estando presente, portanto, nas religiões de matriz africana ou indígena.

Vale destacar que não se trata de compreender os feminismos negros essencialmente fixos e opostos aos feminismos brancos, como muito bem destacou Brah (2006), já que seriam "[...] campos historicamente contingentes de contestação dentro de práticas discursivas e materiais" (p. 331). Na concepção de Brah (2006, p. 358), não tratar os feminismos "negro" e "branco" de modo essencialista implica a possibilidade de mulheres negras e mulheres brancas conjuntamente trabalharem para o surgimento de práticas e experiências feministas não racistas.

Nessa perspectiva, as diferenças entre mulheres brancas e negras não estão em suas essências, mas se apresentam como "[...] diferença de condições sociais" (BRAH, 2006, p. 341). Ao mesmo tempo, não se trata de considerar que termos como mulher ou mulheres deixaram de ser úteis só porque é indispensável que sejam entendidos como conceitos que abarcam múltiplas experiências e vivências.

O signo "mulher" tem sua própria especificidade constituída dentro e através de configurações historicamente específicas de relações de gênero. Seu fluxo semiótico assume significados específicos em discursos de diferentes "feminilidades" onde vem a simbolizar trajetórias, circunstâncias materiais e experiências culturais históricas particulares. [...] Aqui o foco analítico está colocado na construção social de diferentes categorias de mulheres dentro dos processos estruturais e ideológicos mais amplos. Não se afirma que uma categoria individual é internamente homogênea. Mulheres da classe trabalhadora, por exemplo, compreende grupos muito diferentes de pessoas tanto dentro quanto entre diferentes formações sociais (BRAH, 2006, p. 341).

Dessa forma, Brah (2006) demonstra como não é possível falar de categorias de forma unificada, nem quando se fala de mulheres, nem quando se fala de mulheres negras, mulheres brancas ou mulheres trabalhadoras. A autora compreende que as "estruturas de classe, racismo, gênero e sexualidade não podem ser tratadas como 'variáveis independentes' porque a opressão de cada uma está inscrita dentro da outra - é constituída pela outra e é constitutiva dela" (p. 351). Em outro trecho, Brah (2006) adiciona que "parece imperativo que não compartimentalizemos opressões, mas em lugar disso formulemos estratégias para enfrentar todas elas na base de um entendimento de como se interconectam e articulam" (p. 376). E essa perspectiva por ela apresentada demonstra mais uma vez de que modo as bases para a construção do conceito de interseccionalidade surgiram a partir das vivências e escritas dos feminismos negros.

\section{A interseccionalidade nomeada}

Não raro, alguns estudos acerca da interseccionalidade consideram que ela surgiu entre as décadas de 1980 e 1990 nos Estados Unidos. Portanto, é recorrente que os históricos sobre o conceito partam das contribuições altamente relevantes de Kimberlé Crenshaw, que, em verdade, é responsável por nomear e por produzir pesquisas que contribuíram para a melhor compreensão do conceito e da sua popularização no mundo acadêmico. A autora tem diversas pesquisas nas quais é possível observar de que forma a interseccionalidade surge enquanto uma metáfora (1989), passa a ser entendida como uma categoria analítica (1991) e um conceito provisório (1997).

Em 1989, em um texto menos conhecido, porém o primeiro no qual surge o conceito, Crenshaw (1989) examinou o modo pelo qual a tendência de tratar raça e gênero como categorias de análises e de experiências concretas como sendo mutuamente exclusivas se perpetua devido à forma de eixo-único que domina a produção das leis contra a discriminação racial e as teorias feministas e antirracistas. A autora argumentou que esse modo de eixo-único invisibiliza as mulheres negras na conceitualização, identificação e na remediação quanto à discriminação de raça e gênero, sendo limitadas pelas experiências dos outros membros do grupo, mais privilegiados - no caso do movimento antirracista os privilegiados são os homens negros, e no caso da discriminação de gênero as mais privilegiadas são as mulheres brancas - criando análises distorcidas sobre racismo e discriminação de gênero (CRENSHAW, 1989, p. 140). Desse modo, a autora destacou que a distorção nas análises e legislações ocorre porque "[...] as concepções operativas de raça e sexo se tornam ancoradas em experiências que, na realidade, representam apenas um subconjunto de um fenômeno muito mais complexo"s (CRENSHAW, 1989, p. 140). Ao buscar compreender essa realidade complexa-que, como abordado nas páginas anteriores, é uma preocupação antiga de muitas acadêmicas e/ou militantes dos feminismos negros-, Crenshaw lança mão do que ela nomeia como interseccionalidade, para abandonar propostas pautadas em categorias monolíticas de análises ou que, no máximo, as consideram de forma meramente aditivas.

\footnotetext{
${ }^{5}$ No original: "[...] the operative conceptions of race and sex become grounded in experiences that actually represent only a subset of a much more complex phenomenon" (CRENSHAW, 1989, p. 140).
} 
Logo, são poderosas as contribuições de Crenshaw para a compreensão e popularização da interseccionalidade. Isso não significa dizer que é razoável apagar o que vinha ocorrendo antes de 1989. Trata-se de um grave lapso de algumas pesquisas sobre interseccionalidade, algo não pretendido por Crenshaw, já que seus textos tomaram como fundamento e reconheceram a importância de pesquisas e tópicos de movimentos sociais anteriores ao seu ato de nomear a interseccionalidade.

Assim sendo, é importante rejeitar eventuais entendimentos que ignoram ou minimizam que a origem da interseccionalidade está relacionada com os movimentos sociais e, portanto, seu surgimento e potencial não se reduz à compreensão e aos limites impostos pela/na academia. Mais do que uma imprecisão teórica, apagar o histórico da origem da interseccionalidade tende a promover o silenciamento de um grande grupo de mulheres negras e contribui para que gradativamente o conceito da interseccionalidade perca sua força e potência crítica - como se vê nas próximas linhas.

As sociólogas Patricia Hill Collins e Sirma Bilge lançaram, em 2016, o livro intitulado Intersectionality, no qual as autoras demonstram como a ausência sobre os movimentos sociais nos históricos sobre a interseccionalidade não é apenas uma lacuna na contextualização do conceito, mas, sobretudo, um equívoco ao assumir que a interseccionalidade se resume a mais um campo acadêmico (COLLINS; BILGE, 2016, p. 64), ignorando que a interseccionalidade parte da sinergia entre a pesquisa crítica (critical inquiry) e a práxis crítica (critical praxis); sendo assim, as autoras compreendem a interseccionalidade a partir desses dois pontos focais. Enquanto o primeiro diz respeito ao desenvolvimento da interseccionalidade na academia como ferramenta analítica para a construção de pesquisas e análises críticas; o segundo se refere à forma como as pessoas, seja individualmente, seja enquanto coletivos, produzem e usam a estrutura da interseccionalidade no seu dia a dia (COLLINS; BILGE, 2016, p. 32). Desse modo, considerar a história da interseccionalidade como tendo iniciado a partir do momento em que o termo foi nomeado por Crenshaw em 1989 é apagar uma parcela altamente relevante da história e do propósito do próprio conceito, sua práxis crítica.

De modo semelhante, Anna Carastathis (2016, p. 51), em seu livro Intersectionality: origins, contestations, horizons, também compreende que, contextualizando corretamente a interseccionalidade, ela deve ser entendida como representando uma síntese entre os movimentos sociais e o conhecimento acadêmico crítico. O já citado discurso de Sojourner Truth, "Não sou uma mulher?", é um dos mais emblemáticos exemplos de como a experiência cotidiana das mulheres negras é perpassada e reconhecida para além do conceito de gênero/sexo muito antes do surgimento do conceito da interseccionalidade. Por essa razão, Carastathis (2016), assim como Collins e Bilge (2016), traça a trajetória da interseccionalidade na esfera dos movimentos sociais dos Estados Unidos e evidencia que a interseccionalidade, antes de ser nomeada na academia por Kimberlé Crenshaw, já era parte da práxis de um grande número de pessoas e grupos que militavam por acesso a direitos e pela eliminação das desigualdades sociais.

Collins e Bilge (2016, p. 65) apresentam as décadas de 1960 e 1970 como sendo um período de grande importância para a elaboração do âmago do que viria a ser nomeado como interseccionalidade. As autoras que escrevem a partir da história dos Estados Unidos demarcam esse período, pois é nele que surgiram os impactos de uma longa política de segregação racial nos Estados Unidos, o que fez com que as mulheres não brancas ("women of color") estivessem ao mesmo tempo em diálogo e em tensão com diferentes movimentos por direitos, dentre eles: a luta pelos direitos civis (das mulheres e das pessoas negras), Black Power, Chicano Liberation, Red Power e os movimentos Asian-American. Nesse cenário, ficou evidente às mulheres afro-americanas que não podiam combater as opressões que enfrentavam com mecanismos que consideravam apenas a raça, o gênero, a classe ou a sexualidade de forma exclusiva (COLLINS; BILGE, 2016, p. 65).

É no final da década de 1970 e ao longo da década de 1980 que Collins e Bilge (2016, p. 76) compreendem que os movimentos sociais começam a articular alguns vocabulários e ideias ainda mais próximas da interseccionalidade. Com termos como duplo risco (double jeopardy) de raça e gênero no contexto do capitalismo, os movimentos articulavam mais de uma categoria de opressão para dar conta da realidade cotidiana de grande parte das pessoas que militava nos movimentos sociais.

Nossa leitura próxima das obras selecionadas da produção intelectual das mulheres de cor durante os anos formativos da interseccionalidade revela sua combinação verdadeiramente original: uma maneira de interconectar experiências pessoais e análises estruturais de opressões

\footnotetext{
${ }^{6}$ Ao longo do texto, a expressão women of color, quando em tradução indireta, será traduzida como 'mulheres não brancas'. Essa escolha se deve ao fato de que, no Brasil, a expressão 'mulheres de cor' não possui a mesma significação que a expressão women of color possui nos Estados Unidos, já que se refere não apenas às mulheres afrodescendentes, como também às latinas e às indígenas.
} 
interligadas sem contornar o significado de experiências de vida, identificações múltiplas e comunidades políticas (COLLINS; BILGE, 2016, p. 76-77). ${ }^{7}$

É interessante observar que a interseccionalidade pode ser compreendida como algo que vem de fora para dentro da academia, tanto por ser parte da práxis de diversos coletivos existentes nas décadas anteriores ao surgimento e apropriação do termo pelas universidades, como também porque foi essa persistente militância que fez com que, nos Estados Unidos, algumas instituições buscassem responder às críticas desses movimentos contratando pessoas de grupos até então quase que totalmente excluídos desses espaços (COLLINS; BILGE, 2016, p. 77). Ou seja, a inserção no campo acadêmico de muitas das pessoas que futuramente irão desenvolver pesquisas sobre interseccionalidade deve-se, em parte, à própria luta travada pelos movimentos sociais entre as décadas de 1960 e 1980. "Ganhar acesso a cargos acadêmicos permite que as mulheres afroamericanas tragam ideias da política feminina negra com elas para a academia através dos duplos fluxos de feminismo negro e estudos sobre raça/classe/gênero" (COLLINS; BILGE, 2016, p. 78). ${ }^{8}$ Ignorar a importância dessas três décadas para a interseccionalidade é uma forma de apagamento que envolve uma subentendida hierarquização entre o saber acadêmico e a práxis.

As discussões do item anterior acerca dos feminismos negros apresentam algumas das características que marcaram as discussões sobre gênero e raça muito antes do surgimento do conceito da interseccionalidade. Tanto no livro de Carastathis (2016) como no de Collins e Bilge (2016), é possível encontrar sólidos históricos acerca das discussões acadêmicas que precederam a nomeação da interseccionalidade. Vale destacar, ainda, que as discussões desenvolvidas no Brasil, em especial pelos feminismos negros após o fim da ditadura militar, também tornaram visível a busca por articular gênero, raça e classe de modo crítico.

Nesse sentido, vale mencionar o texto da cientista política Sonia Alvarez $(2014$, p. 16) no qual, com o propósito de revisar as epistemologias para bem de repensar as dinâmicas existentes nos feminismos do Brasil e da América Latina, a autora aborda a complexidade sempre existente dentro desses movimentos feministas. De acordo com Alvarez, é possível afirmar que em nenhum momento houve na região um feminismo uno. Ocorreram, todavia, disputas internas e externas e a predominância no alcance de espaços e de voz, ou seja, "em diferentes momentos, distintas/os autoras/es ou vertentes ganham maior ou menor visibilidade política e cultural, e maior ou menor acesso ao microfone público e aos recursos materiais e culturais, às vezes conseguindo se estabelecer como hegemônicos" (ALVAREZ, 2014, p. 18) de tal modo que, "apesar de essa hegemonia discursiva ter delimitado estreitamente o que e quem compunha 'o' movimento feminista, o campo feminista contemporâneo no Brasil e em muito da América Latina de fato já nasceu plural e heterogêneo" (p. 23).

Tal afirmação de Sonia Alvarez afasta a ideia de que as lutas que envolvem outras categorias além do gênero poderiam resultar no enfraquecimento dos movimentos feministas, já que, na verdade, essa pluralidade de visões é um elemento intrínseco do(s) feminismo(s). Quando, no Brasil, nas décadas de 1970 e 1980, se criam organizações autônomas tanto com relação ao movimento feminista como quanto ao movimento negro, muitas mulheres negras denunciavam a "tripla discriminação" e interpelavam o feminismo hegemônico da época, já abraçando a necessidade de se pensar as questões de gênero relacionadas com as questões de raça e classe (ALVAREZ, 2014, p. 24).

Dessa forma, fica notório que, mesmo sem a existência do conceito da interseccionalidade, existia o reconhecimento de uma "tripla discriminação" ou de um duplo risco (double jeopardy) que assolava a vida das mulheres negras, bem como das mulheres indígenas. Contudo, essa preocupação não tinha o alcance e a visibilidade que hoje possui o conceito da interseccionalidade.

Ana Claudia Jaquetto Pereira (2016), em sua tese de doutoramento, aborda a "'Interseccionalidade', palavra de sonoridade estranha aos ouvidos de falantes da língua portuguesa" (p. 50). Dentre outras contribuições, vale mencionar que a autora sistematiza algumas das mais importantes disputas em torno do conceito. Ao abordar as críticas desenvolvidas por autoras que denunciam a possibilidade de esvaziamento da interseccionalidade ao distanciála de sua origem nos movimentos sociais, Pereira (2016) acaba por oferecer uma análise altamente relevante sobre a cisão no emprego da interseccionalidade "[...] em abordagens que empregam gênero, raça e outras categorias correlatas como marcadores identitários de diferença daquelas que os mobilizam enquanto marcadores de desigualdades sociais" (p. 21). Desse modo, torna-se

\footnotetext{
${ }^{7}$ No original: "Our close reading of selected works from women of color's intellectual production during intersecctionality's formative years uncovers its truly original combination: a way of interconnecting personal experiences and structural analyses of interlocking oppressions without skirting the meaning of life experiences, multiple identifications, and political communities" (COLLINS; BILGE, 2016, p. 76-77).

${ }^{8}$ No original: "Gaining access to academic positions enable African-American women directly to bring ideas from black feminist politics with them into the academy through the dual streams of black feminism and race/class/gender studies" (COLLINS; BILGE, 2016, p. 78).
} 
notório que nem todos os usos da interseccionalidade coadunam com a perspectiva proposta por Crenshaw (1989; 1991; 1997), na qual categorias como gênero, raça, sexualidade, classe, nacionalidade, dentre outras, deveriam ser articuladas em análises interseccionais capazes de fundamentar legislações e políticas públicas voltadas a sanar essas desigualdades estruturais.

O debate sobre a visibilidade ou o apagamento do contexto histórico, políico e social de surgimento da interseccionalidade dialoga, portanto, com os próprios usos que têm sido feitos do conceito, em particular após sua maior popularização. Em sua pesquisa, Pereira (2016) aborda algumas dessas disputas e apresenta, dentre outros argumentos, aquele que entende que

[...] a disseminação da interseccionalidade tem sido facilitada por sua inserção em uma lógica reificante, de acordo com a qual a adesão ao termo denota adesão ao politicamente correto e ao que há de mais atualizado no discurso feminista. Ao mesmo tempo, este uso prioriza a menção ao termo, descolado de seu contexto, da bagagem que o envolve e de sua história, o que impede o uso efetivo da ideia a que ele esteve originalmente atrelado. Tamanha disparidade em relação à proposta original levou a própria Crenshaw (apud ALEXANDER-FLOYD, 2012) a lamentar que a multiplicação de categorias identitárias tenha ganhado mais espaço do que a análise estrutural e a crítica política nos contextos de aplicação da expressão (p. 61).

Desse modo, a preocupação com o adequado (re)conhecimento das origens da interseccionalidade ocorre no mesmo cenário de preocupação com o esvaziamento do conceito e de sua utilização como mera retórica política.

A popularização da interseccionalidade, portanto, é atualmente um fato. Mas a sua utilização na abordagem de fenômenos que perpassam as relações de gênero e raça nem sempre é entendida como indispensável. Sobre isso, Carneiro (2017) afirmou em uma entrevista que:

Eu nunca usei esse conceito porque eu sou muito anterior à emergência dele, embora os sentidos que ele carrega estejam presentes nos meus textos e de outras mulheres negras da minha geração. Quando Crenshaw chegou com esse debate da interseccionalidade, eu já estava com essa concepção consolidada de feminismo negro (CARNEIRO, 2017, p. 18 [grifos nossos]).

Nesta fala, Carneiro demonstra como não apenas nos Estados Unidos, mas também no Brasil, os debates que consideravam gênero, raça e classe já eram parte das discussões na militância política e na produção acadêmica. É inegável, portanto, que o conceito de interseccionalidade é tributário dos debates que vinham ocorrendo dentro dos feminismos, enquanto movimento social, especialmente dos feminismos negros. Isso se deu em razão dos questionamentos que os feminismos negros fizeram sobre os propósitos de um movimento majoritariamente centrado em questões que afetavam mulheres brancas, heterossexuais e de classe média, momento no qual se proliferaram as reivindicações por um feminismo capaz de atender também às demandas de mulheres negras, indígenas, homossexuais, transexuais, pobres, migrantes, gordas, com deficiências, entre outras.

Ao se reconhecer a importância dos movimentos sociais e das lutas por direitos travadas fora dos muros da academia, não se pretende diminuir a relevância da pesquisa e mesmo do próprio ato de nomear desempenhado por Kimberlé Crenshaw em 1989. Trata-se apenas de compreender a interseccionalidade a partir da própria história que Crenshaw abarcou em seus estudos e, nos termos de Collins e Bilge (2016), enquanto pesquisa crítica e como práxis crítica. Somente assim será possível que a popularização do conceito não resulte em apagamento de seu potencial crítico-transformador e das lutas e falas de mulheres negras que o antecederam.

\section{Conclusão}

A proposta central da presente pesquisa foi realizar um apanhado geral do momento anterior ao surgimento do conceito da interseccionalidade. Tal objetivo surge em um contexto no qual a interseccionalidade tem sido cada vez mais utilizada em pesquisas no campo das discussões de gênero, inclusive no Brasil. Assim sendo, buscou-se apresentar alguns elementos que podem servir de subsídios para uma melhor compreensão do conceito, por meio de uma aproximação com seus antecedentes.

Neste artigo foram abordadas as discussões relativas à raça e aos feminismos negros e evidenciou-se os elementos que foram basilares para que houvesse um contexto possível de surgimento da interseccionalidade. Sem a pretensão de esgotar qualquer uma dessas temáticas, foi realizada uma sólida revisão bibliográfica capaz de traçar um panorama rico acerca do período e dos debates anteriores ao surgimento da interseccionalidade, quando nomeada por Kimberlé Crenshaw, em 1989.

Foi possível reconhecer que a interseccionalidade veio suprir uma lacuna analíitica - dentro do campo científico-acadêmico - sobre as relações de opressão que surgem para além das relações de gênero e que com ela dialogam. Ao considerar que a experiência cotidiana das 
pessoas envolve simultaneamente diversas categorias identitárias que socialmente constituem distintos marcadores sociais de desigualdade, a interseccionalidade buscou contribuir para análises que lidem melhor com a complexidade existente no mundo. É preciso que as contribuições teóricas e acadêmicas em torno do conceito reconheçam que são tributárias de lutas, reivindicações e teorias que têm como principais agentes as mulheres negras. Somente dessa forma é possível que o conceito não perca seu potencial realmente transformador e que sua utilização não reforce o silenciamento e o apagamento das importantíssimas contribuições que historicamente e contemporaneamente são concretizadas pelas mulheres negras na teoria e na prática feminista.

\section{Referências}

ALVAREZ, Sonia E. "Para além da sociedade civil: reflexões sobre o campo feminista". Cadernos Pagu, Campinas, v. 43, p. 13-56, jan./jun. 2014.

BRAH, Avtar. "Diferença, diversidade, diferenciação". Cadernos Pagu, Campinas, v. 1, n. 26, p. 329-376, jan./jun. 2006.

CARASTATHIS, Anna. Intersectionality: origins, contestations, horizons. Nebraska: University of Nebraska Press, 2016.

CARNEIRO, Sueli. "Mulheres em movimento". Estudos Avançados, São Paulo, v. 17, n. 49, p. 11 17-132, dez. 1995.

CARNEIRO, Sueli. "Sobrevivente, testemunha e porta-voz". CULT, São Paulo, n. 223, p. 12-20, maio 2017. (Entrevista concedida à Bianca Santana)

CARNEIRO, Sueli. "Enegrecer o feminismo: a situação da mulher negra na América Latina a partir de uma perspectiva de gênero". In: ASHOKA EMPREENDIMENTOS SOCIAIS; TAKANO CIDADANIA (Orgs.). Racismos contemporâneos. Rio de Janeiro: Takano, 2003. p. 49-58.

COLLINS, Patricia Hill. "Rasgos distintivos del pensamiento feminista negro". In: JABARDO, Mercedes (Ed.). Feminismos negros: una antología. Madrid: Traficantes de Sueños, 2012. p. 99-134.

COLLINS, Patricia Hill; BILGE, Sirma. Intersectionality. Cambridge: Polity Press, 2016.

CRENSHAW, Kimberlé. "Demarginalizing the intersection of race and sex: a black feminist critique of antidiscrimination doctrine, feminist theory and antiracist politics". The University of Chicago Legal Forum, n. 140, p. 139-167, 1989.

CRENSHAW, Kimberlé. "Mapping the margins: intersectionality, identity politics, and violence against women of color". Stanford Law Review, v. 43, n. 6, p. 1241-1299, jul. 1991.

CRENSHAW, Kimberlé. "Beyond racism and misogyny: black feminism and 2 live crew". In: MEYERS, Diana Tietjens (Org.). Feminist social thought: a reader. New York and London: Routledge, 1997. p. 246-263.

DAVIS, Angela. Mulheres, raça e classe. Tradução de Heci Regina Candiani. São Paulo: Boitempo, 2016.

FREYRE, Gilberto. Casa-grande e senzala: formação da família brasileira sob o regime da economia patriarcal. 51. ed. São Paulo: Global, 2006.

GOMES, Nilma Lino. "Alguns termos e conceitos presentes no debate sobre relações raciais no Brasil: uma breve discussão". In: BRASIL. Educação anti-racista: caminhos abertos pela lei federal n० 10.639/03. Brasília: MEC, Secretaria de Educação Continuada e Alfabetização e Diversidade, 2005. p. 39-62.

GONZALEZ, Lélia; HASENBALG, Carlos. Lugar de Negro. Rio de Janeiro: Marco Zero, 1982.

GONZALEZ, Lélia. "Racismo e sexismo na cultura brasileira". Ciências Sociais Hoje, São Paulo, p. 223-244, 1984.

hooks, bell. "Mulheres negras: moldando a teoria feminista". Revista Brasileira de Ciência Política, Brasília, v. 1, n. 16, p. 193-210, jan./abr. 2015.

KYRILLOS, Gabriela Moraes; STOLZ, Sheila. "Políticas indigenistas no Brasil: passado assimilacionista, futuro emancipatório?". Revista Jurídica, UNICURITIBA: Curitiba, v. 1, n. 30, p. 91-111, jan. 2013. 
LOPES, Joyce Souza. "Pontuações e proposições ao branco/a e à luta antirracista: ensaio políticoreflexivo a partir dos estudos críticos da branquitude". In: V SIMPÓSIO INTERNACIONAL LUTAS SOCIAIS NA AMÉRICA LATINA. Anais... Paraná, 2013, p. 134-150.

MUNANGA, Kabengele. "Mestiçagem como símbolo da identidade brasileira". In: SANTOS, Boaventura de Sousa; MENESES, Maria Paula (Orgs.). Epistemologias do Sul. São Paulo: Cortez, 2010.

OYìù̀Mí, Oyèrónké. "Conceitualizando o gênero: os fundamentos eurocêntricos dos conceitos feministas e o desafio das epistemologias africanas". CODESRIA Gender Series, Dakar, v. 1, p. 1-8, 2004.

PEREIRA, Ana Claudia J. Pensamento social e político do movimento de mulheres negras: o lugar de ialodês, orixás e empregadas domésticas em projetos de justiça social. 2016. 245f. Tese (Doutorado em Ciência Política) - Instituto de Estudos Sociais e Políticos, Universidade do Estado do Rio de Janeiro, Rio de Janeiro, 2016.

RIBEIRO, Darcy. Os brasileiros - livro I: teoria do Brasil. 5. ed. Petrópolis: Vozes, 1980.

VELASCO, Mercedes Jabardo. "Introducción. Construyendo puentes: en diálogo desde/con el feminismo negro". In: JABARDO, Mercedes (Ed.). Feminismos negros: una antología. Madrid: Traficantes de Sueños, 2012. p. 27-56.

Gabriela M. Kyrillos (gabrielamkyrillos@gmail.com) é Professora da Faculdade de Direito da Universidade Federal do Rio Grande (FURG). Doutora em Direito pela Universidade Federal de Santa Catarina (PPGD/UFSC) e pós-doutora em Direito e Justiça Social pela FURG. Mestra em Política Social pela Universidade Católica de Pelotas e graduada em Direito pela Universidade Federal do Rio Grande (FURG).

\section{COMO CITAR ESSE ARTIGO DE ACORDO COM AS NORMAS DA REVISTA}

KYRILLOS, Gabriela M. "Uma Análise Crítica sobre os Antecedentes da Interseccionalidade". Revista Estudos Feministas, Florianópolis, v. 28, n. 1, e56509, 2020.

CONTRIBUIÇÃO DE AUTORIA

Não se aplica.

FINANCIAMENTO

Bolsa CAPES de Doutoramento (2014-2018) e Bolsa CAPES-PNPD (2018-2019)

CONSENTIMENTO DE USO DE IMAGEM

Não se aplica.

APROVAÇÃO DE COMITÊ DE ÉTICA EM PESQUISA

Não se aplica.

CONFLITO DE INTERESSES

Não se aplica.

LICENÇA DE USO

Este artigo está licenciado sob a Licença Creative Commons CC-BY Internacional. Com essa licença você pode compartilhar, adaptar, criar para qualquer fim, desde que atribua a autoria da obra.

HISTÓRICO

Recebido em 24/04/2018

Reapresentado em 04/05/2019

Aprovado em 02/08/2019 